Erratum to: A framework for supporting tree-like indexes on the chord overlay. JOURNAL OF COMPUTER SCIENCE AND TECHNOLOGY 35(2): inside back cover Mar. 2020. DOI 10.1007/s11390-013-1405-6

\title{
Erratum to: A Framework for Supporting Tree-Like Indexes on the Chord Overlay
}

Published Online: December 23, 2013.

Erratum: Ming-Dong Zhu, De-Rong Shen, Yue Kou, Tie-Zheng Nie, Ge Yu. A Framework for Supporting Tree-Like Indexes on the Chord Overlay. Journal of Computer Science and Technology 2013, 28(6): 962-972. DOI: 10.1007/s11390-013-1391-8.

"The publisher regrets the error made to the metadata published with the paper entitled "A Framework for Supporting Tree-Like Indexes on the Chord Overlay" in Volume 28, Issue 6, November 2013, pp.962-972. The third author's name should read: Yue Kou. The citation listed on the SpringerLink article (DOI 10.1007/s11390-0131391-8) is correct." 